ミニレビュー

\title{
Immunoelectron microscopic studies on the behavior of LHCP II in Euglena
}

\section{Tetsuaki Osafune}

Department of Life Science, Nippon Sport Science University, Aobaku, Yokohama 227, Japan

Keywords. Light-harvesting chlorophyll $a / b$ complex, LHCP II apoprotein, Golgi, compartmentalized osmiophilic structure (COS), Euglena.

\begin{abstract}
Cells of Euglena contain a light-harvesting chlorophyll $a / b$ complex associated with photosystem II. In Euglena, the formation of the $26.5 \mathrm{kDa}$ principal light-harvesting chlorophyll $a / b$ binding protein of photosystem II (LHCP II) has a number of unusual features. The precursors to LHCP II are large polyproteins containing multiple copies of LHCP II, and photocontrol of their formation is largely translational. Under conditions favoring LHCP II accumulation in the thylakoids, a reaction with anti-LHCP II antibody can be observed in the Golgi by immunogold electron microscopy. The timing of the immunoreaction in the Golgi in synchronous cells and in cells undergoing normal light-induced chloroplast development suggests that the nascent LHCP II passes through the Golgi on the way to the thylakoids. The compartmentalized osmiophilic structure (COS) also shows an immunoreation. These observations, and others discussed in this paper, suggest that light permits translation of polyprotein LHCP II precursors on cytoplasmic ribosomes of the rough endoplasmic reticulum (ER) and that these pass through the ER to the Golgi where, presumably, further modifications take place. Since an LHCP II immunoreaction is found in Golgi vesicles, these may transport the nascent LHCP II to the plastid and facilitate its uptake.
\end{abstract}

1Dedicated to the memory of Jerome A. Schiff, the Abraham and Etta Goodman Professor of Biology at Brandeis University, Waltham, Massachusetts, U.S.A. 


\section{Introduction}

The light harvesting chlorophyll $a / b$ protein of photosystem II of Euglena (LHCP II), as in other systems, is encoded in nuclear DNA (Schiff et al.,1991). The principal polypeptide is $26.5 \mathrm{kDa}$ (Cunningham and Schiff,1986) and is transcribed as a large message which is translated on cytoplasmic ribosomes to yield a large polyprotein containing multiple copies of the polypeptide (Houlne and Schantz,1987; Rikin and Schwartzbach,1988; Muchhal and Schwartzbach,1990). The photocontrol of formation of LHCP II apoprotein is exerted primarily at translation (Rikin and Schwartzbach,1989; Weiss et al.,1988) and immunoelectron microscopy indicates the involvement of the compartmentalized osmiophilic structure (COS) and, particularly, the Golgi apparatus and Golgi vesicles in the path leading to eventual deposition in the plastids (Osafune et al., 1990;1991a; 1991b;Schiff et al.,1991).

Cells of Euglena gracilis var. bacillaris or strain Z, grown in darkness aero-bically under the usual conditions (Greenblatt and Schiff,1959) and diluted with a resting medium (Stern et al.,1964a) undergo one or two divisions and then cease growth. When exposed to normal intensities of light $(100-150 \mathrm{ft}-\mathrm{c})$ the proplastids of these resting cells undergo normal development into chloroplasts containing all of the usual components for photosynthesis including the light harvesting antennas of photosystem I and II (Spano et al.,1987;Stern et al., 1964a). If dark-grown resting cells are placed at low intensities of light (about $7 \mathrm{ft}-\mathrm{c}$, the developmental threshold), only rudimentary chloroplasts are formed which lack the photosynthetic antennas including LHCP II (Ben-Shaul et al.,1964; Spano et al.,1987;Stern et al.,1964b). These cells resemble phenocopies of mutants of Euglena (G1BU, Gr1BSL, O4BSL) which lack the photosynthetic antennas but make other components of the photosynthetic apparatus normally (Cunningham and Schiff,1986); thus the cells developing at low intensities or the mutants carry out photosynthesis at saturating light intensities(Stern et al.,1964a,b;Cunningham and Schiff, 1986;Spano et al.,1987). However, unlike the mutants, the low-intensity cells can be induced to form the missing components (the antennas) of the photosynthetic apparatus by exposing them to more normal intensities for chloroplast development (100-150 ft-c) (Spano et al., 1987;Stern et al.,1964b). Under these conditions, chlorophyll $b$ and LHCP II apoprotein are formed and increase rapidly to normal levels (Spano et al.,1987). Thus under the more usual conditions for chloroplast development LHCP II apoprotein does not accumulate when the dark-grown resting cells are exposed to low light intensities at the developmental threshold (Spano et al.,1987).

However, when Euglena cells are grown in darkness on a rich carbon-containing medium under semi-anaerobic conditions, wax (chiefly myristyl myristate) accumulates in visible amounts within the cells (Osafune et al.,1990a,b,c,d;Shihira-Ishikawa et al.,1977). Under these conditions, the development of the proplastid is repressed and only rudimentary proplastid structures are present. On transfer of these wax-rich cells to an inorganic medium containing an ammonium salt in 
darkness under aeration, the proplastid expands and a more elaborate proplastid structure is formed (Osafune et al.,1990c,d; Shihira-Ishikawa et al.,1977). This proplastid appears to be further ahead developmentally than proplastids in cells under the more usual conditions and development is rapid once these wax-rich cells are exposed to normal intensities of light (100-150 ft-c). The situation may be analogous to that in higher plants where simple proplastids formed initially are converted, in darkness, to elaborate etioplasts at the expense of seed reserves. In the case of the wax-rich cells of Euglena, the components and energy required for enhanced development come from the oxidation of wax, and to some extent of paramylum (Osafune et al.,1990c, d; Shihira-Ishikawa et al.,1977).

Euglena cells can be synchronized by various environmental stimuli; one of the more popular methods is to use alternating light and dark periods. Under these conditions, division of cells and organelles occurs during the dark period, but a number of important events for chloroplast development take place in the light period, such as the formation of various plastid thylakoid components of photosynthesis, among them the $26.5 \mathrm{kDa}$ principal LHCP II.

\section{Immunolocalization of LHCP II Apoprotein in the Golgi during Light-induced Chloroplast Deveropment in Non-Dividing Euglena Cells.}

We have already shown that dark-grown resting cells of Euglena gracilis (var. bacillaris or Z strain) treated with antibody to LHCP II apoprotein and protein A-gold, do not show deposition of gold over plastid thylakoids or Golgi (Osafune et al, 1990e;Osafune et al, 1989b) This continues during the first $9 \mathrm{hr}$ of exposure of the dark-grown cells of bacillaris to light (Figs. 1 and 2); although there is no deposition over thylakoids or Golgi, there is staining of the compartmentalized osmiophilic body (COS)(Osafune and Schiff, 1983) at $9 \mathrm{hr}$ (Figs. 1 and 2). By $12 \mathrm{hr}$, however, there is considerable antibody reaction in the Golgi, but only a small ammount of reaction in the plastids (Fig. 3). After this time (for example at $48 \mathrm{hr}$ of light exposure), there is a strong antibody reaction in both Golgi and plastid thylakoids (Fig. 4). Treatment with preimmune serum instead of antiserum at $48 \mathrm{hr}$ does not lead to gold deposition over Golgi or plastids indicating the specificity of the immune reaction. As chloroplast development reaches completion (72 hr of light, Fig. 5) there is little or no immunoreaction to LHCP II apoprotein in the Golgi, but the large ammount of reaction in the plastid thylakoids remains. This continues to $96 \mathrm{hr}$ (Figs. 6 and 7). Similar experiments have been carried out with the $\mathrm{Z}$ strain with the same results (pictures not shown).

Previous studies(Osafune et al, 1992;1990e;1989b; Spano et al.1987) have indicated that LHCP II apoprotein is accumlated by the cells in a strictly light-dependent manner. It is extremely low or undetectable in dark-grown resting cells and, like chlorophyll, shows a low rate of accumulation during the first $12 \mathrm{hr}$, a maximum rate between 24 and $72 \mathrm{hr}$, and accumulation ceases by between 72 and $96 \mathrm{hr}$ (Spano et al.1987). In the present work, we find that this period of accumulation 

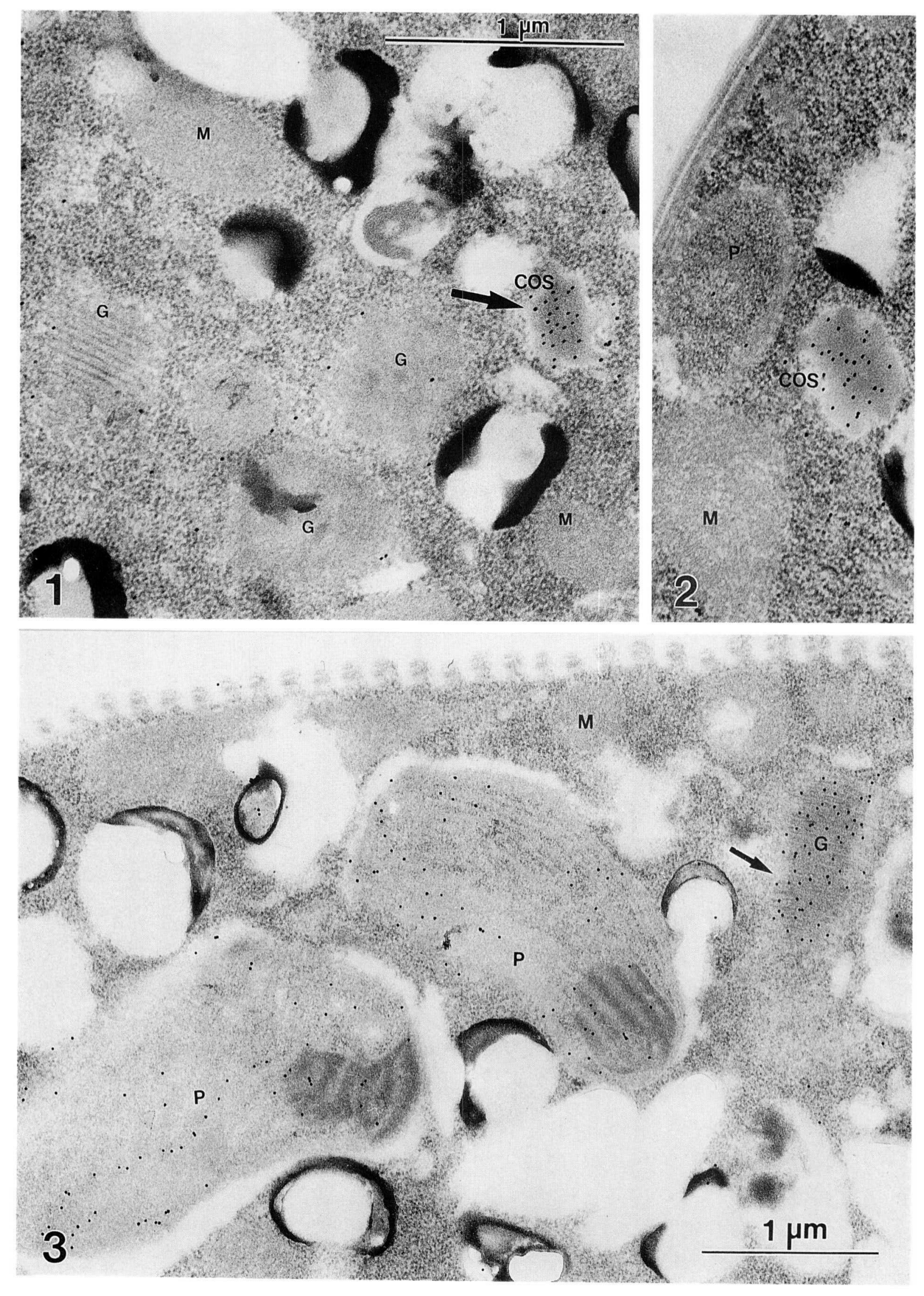


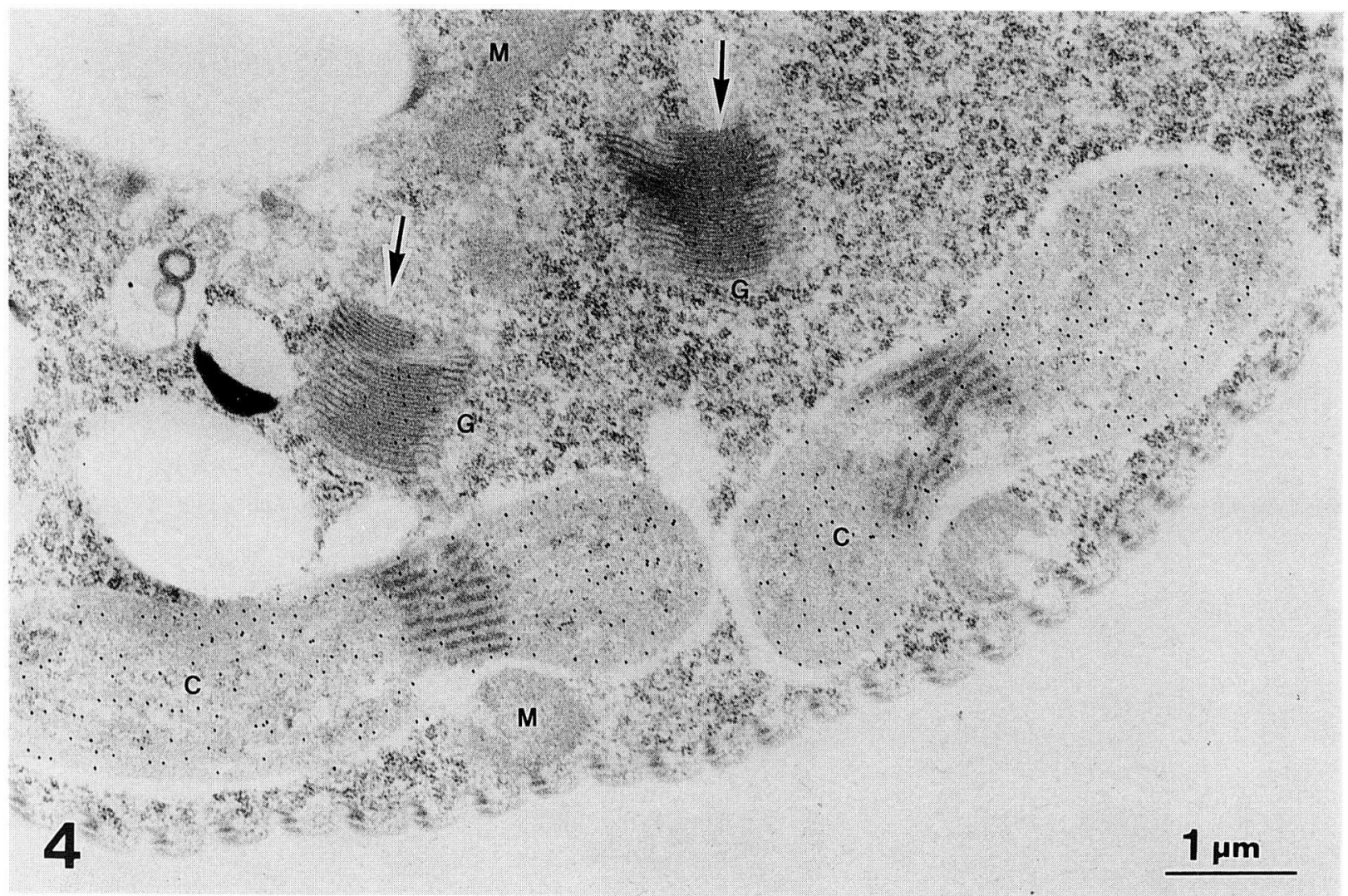

begins with appearance of the apoprotein in the Golgi during the lag period, presumably this material then finds its way into the plastid thylakoids (Osafune et al. 1991b,c,d). This continues throughout the active period of accumulation until LHCP II apoprotein synthesis stops. At this point, material still in the Golgi passes to the thylakoids resulting in a lack of Golgi staining by the end of development(Osafune et al. 1991c,d). Thus the evidence is consistent with a path that leads from synthesis (on cytoplasmic ribosomes) to Golgi to thylakoids. Similar work with synchronous cells of Euglena or a shift up in light intensity in resting cells at the developmental threshold of light intensity ( $7 \mathrm{ft}-\mathrm{c}$ ) have led to the same conclusion, that processing of some sort in the Golgi takes place before the mature LHCP II apoprotein is deposited in the thylakoids. This could take the form of cleavage of an unusually large precursor(Rikin and Schwartzbach, 1989; Houlne and Schants, 1987), other modifications of, or additions to the apoprotein or, perhaps, some assembly of portions of the thylakoid membrane in the Golgi; however, further studies are necessary to indicate which, if any, of these possibilities is correct.

It is not possible, at present, to follow the labeling of the COS in a systematic manner during development because the structure is small and difficult to find. However, a chance observation (Figs. 1 and 2) indicates that the COS shows LHCP II apoprotein immunoreaction before either the Golgi or thylakoids. Random observations in previous work (Osafune et al.,1991b) indicate that the COS is stained at stages in cell synchrony when the Golgi does not show any immunoreaction. 


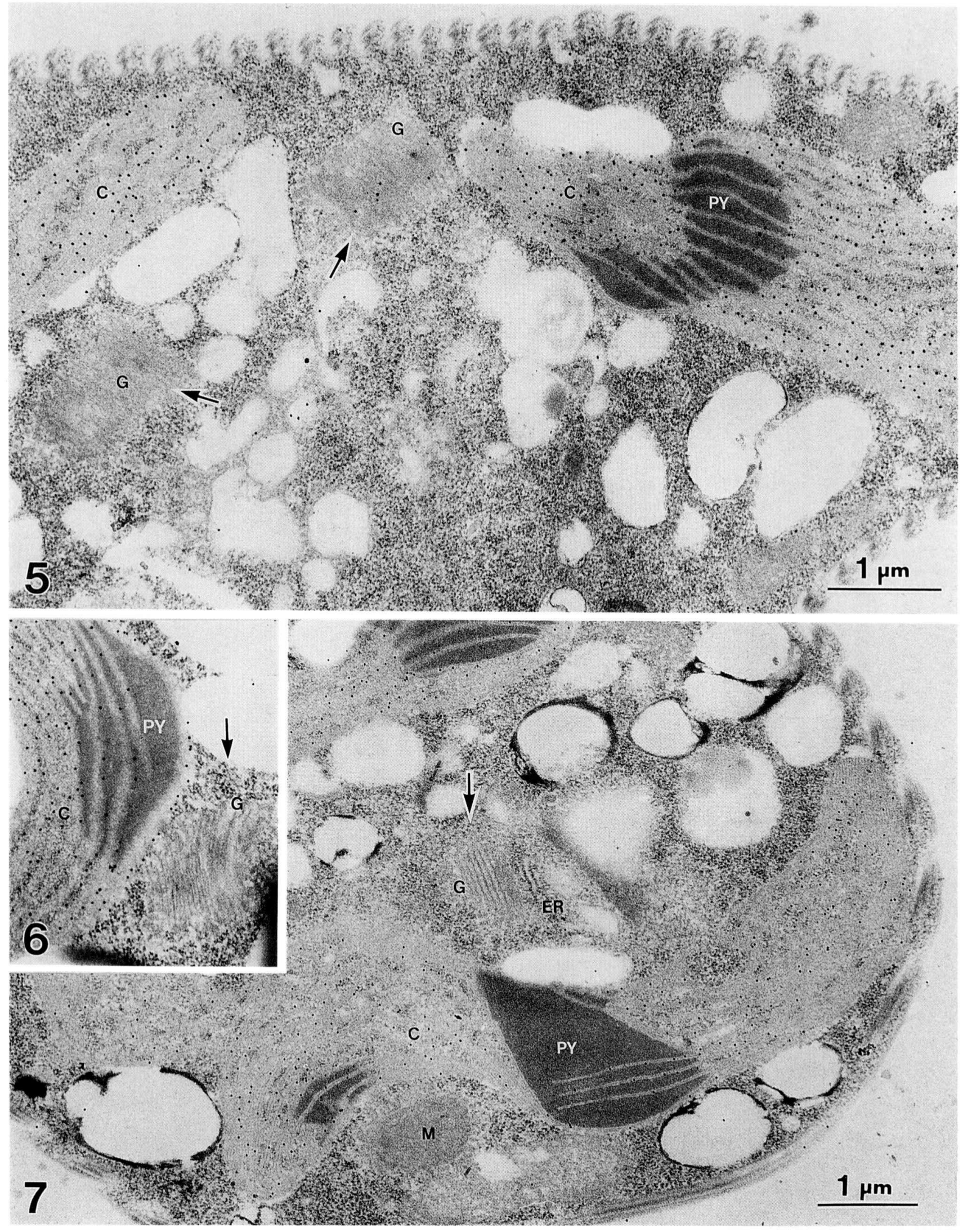


The fact that this "compartmentalized osmiophilic body" appears to surround portions of cytoplasm containing ribosomes and may itself be associated with the endoplasmic reticulum (Osafune and Schiff, 1983) suggests that it may be a site of LHCP II apoprotein synthesis. It so, this would explain why it always seems to be stained even when Golgi and thylakoids are not. Perhaps nascent apoprotein accumulates in the COS until a light signal initiates transfer to the Golgi. This would be consistent with the fact that control of LHCP II apoprotein synthesis appears to be post-transcriptional (Rikin and Schwartzbach,1988; 1989).

Recently, Sulli and Schwartzbach $(1995 ; 1996)$ reported that both LHCP II and the small subunit of RuBisCO are synthesized in the cytoplasm, enter the ER and are transported from the ER to the Golgi and from the Golgi to the chloroplast.

\section{Stage-Dependent Localization of LHCP II in Synchronized Euglena.}

Cells of Euglena gracilis $\mathrm{Z}$ were synchronized by $14 \mathrm{hr}$ light periods alternating with $10 \mathrm{hrs}$ of darkness (Osafune et al.,1991b,d). Observations commenced at the beginning of the light period (zero time) and continued through $14 \mathrm{hr}$ (the end of the light period) to $24 \mathrm{hr}$ (the end of the dark period). As may be seen in Fig. 8, the cell number remains constant throughout the light period and cell division begins at about $18 \mathrm{hr}$ (four hrs into the dark period). Cell samples were obtained throughout the $24 \mathrm{hr}$ period and were prepared for immunoelectron microscopy using protein A-gold and (unless otherwise indicated) specific rabbit antibody against the $26.5 \mathrm{kDa}$ LHCP II apoprotein (Cunningham and Schiff,1986; Rikin and Schwartzbach, 1989) the princepal polypeptide of the Euglena LHCP II light harvesting a/b complex (Cunningham and Schiff,1986).

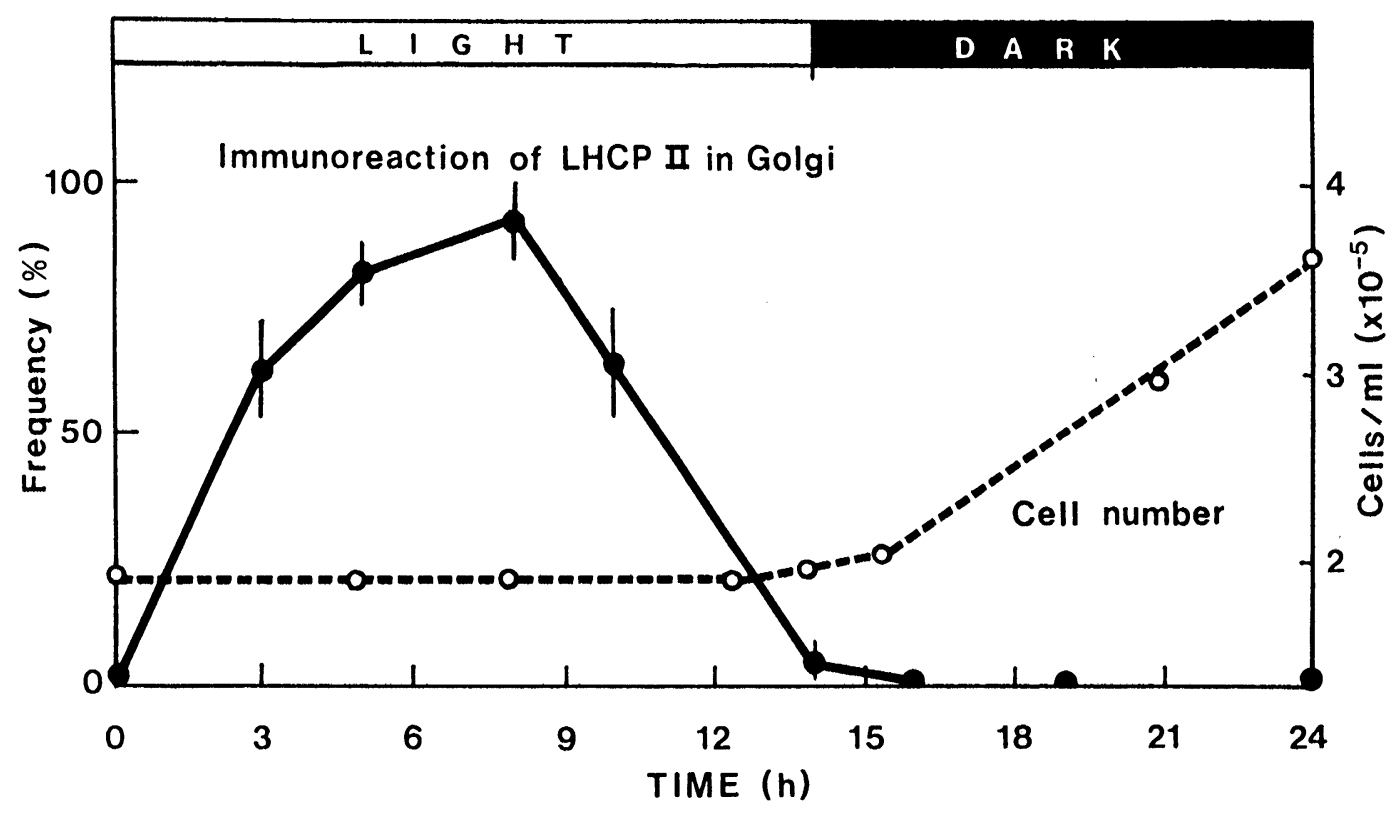




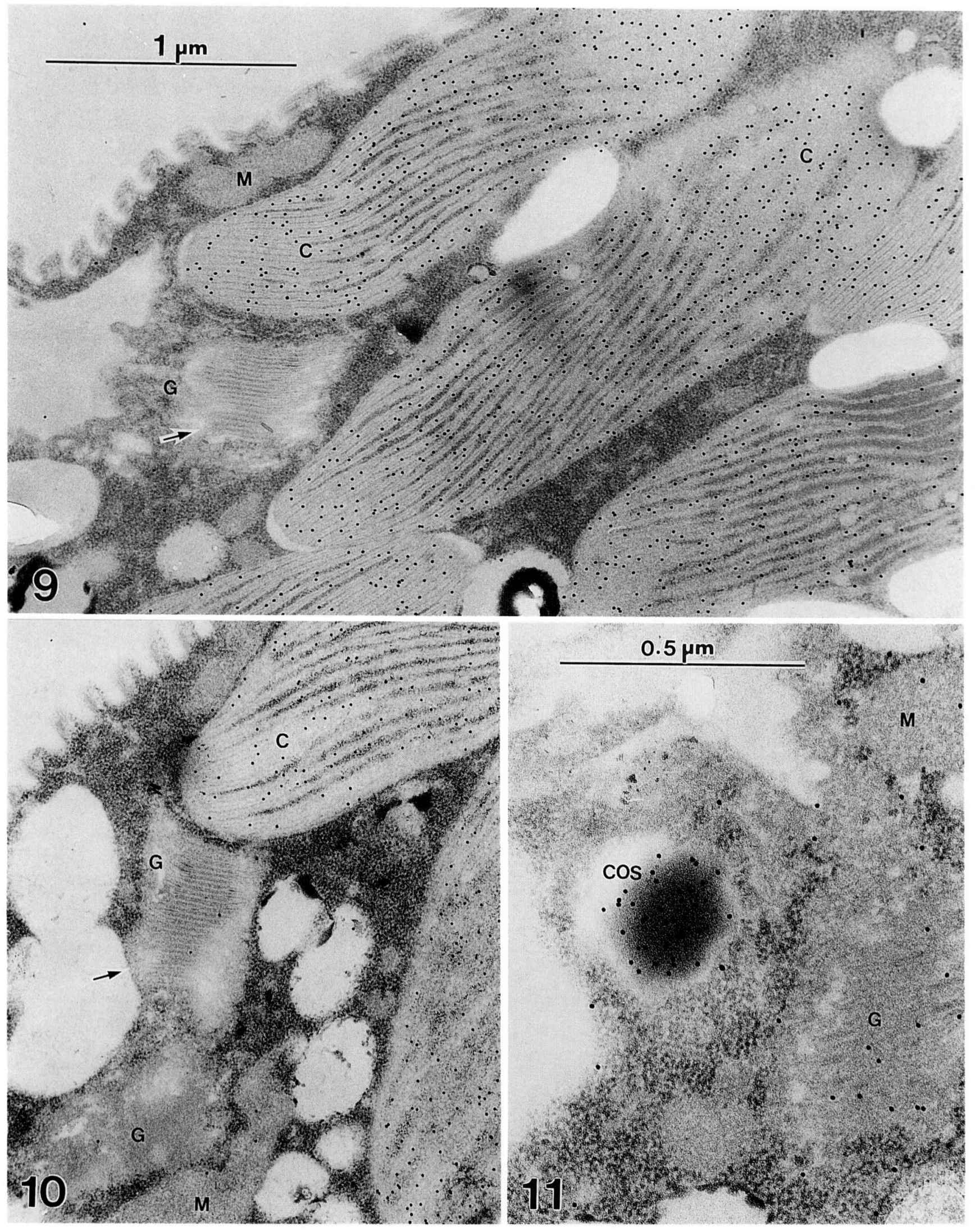


Figures 9 and 10 show two of a series of serial sections through a cell at $0 \mathrm{hr}$ (the beginning of the light period). Gold particles are concentrated over the thylakoids but few are found over the Golgi indicating that LHCP II apoprotein is present in the thylakoids but not in the Golgi at this stage. Figure 11 shows that gold particles, indicating the presence of LHCP II apoprotein, are present over the compartmentalized osmiophilic structure (COS) at $1 \mathrm{hr}$. This structure is composed of a central osmiophilic core with reticulate extentions of the same material surrounding cytoplasmic material including ribosomes (Osafune and Schiff, 1983) and is found in various cells of Euglena gracilis and mutants (Osafune and Schiff, 1983).

At $5 \mathrm{hr}$, gold particles are concentrated over the Golgi apparatus and thylakoids indicating the presence of LHCP II apoprotein in both. A similar section was treated with preimmune, rather than immune serum. There are very few gold particles and these are distributed randomly over the section (data not shown). Thus the reaction obtained appears to be due to the anti-LHCP II apoprotein antibodies in the immune serum.

At $10 \mathrm{hr}$ into the light period, (Fig. 12) gold particles are concentrated over thylakoids and Golgi; at high magnification (Fig.13), the localization within the Golgi can be seen more clearly and, once again, gold particles are seen over the COS. At high magnification, using smaller gold particles, the antibody reaction can be seen to be associated with both the Golgi cisternae and the dense material that lies between them. To be absolutely sure of this, the same material was prepared by freeze-substitution method and the same results were obtained.

At $23 \mathrm{hr}$ ( $9 \mathrm{hr}$ into the dark period) gold label was localized over the thylakoids (of the daughter chloroplasts), but was absent from the Golgi (Fig. 14).

The preceding information plus additional material not shown is summarized in the quantitaive presentation in Fig. 8. The frequencey of Golgi stained with gold is plotted against time. The frequency of staining is the number of Golgi stained over the total number counted (stained plus unstained) times 100. As can be seen, there is no staining of the Golgi at the beginning of the light period $(0 \mathrm{hr})$, but staining soon appears and a broad peak is found in the frequency of Golgi staining between 3 and $10 \mathrm{hr}$ into the light period, with a maximum at $8 \mathrm{hr}$. By 14-16 hr the Golgi no longer show gold deposition and this contiues to the end of the dark period at $24 \mathrm{hr}$. The thylakoids remain stained with immunogold throughout the 0 to $24 \mathrm{hr}$ period.

Brandt and Von Kessel (1983) studied the incorporation of ${ }^{14} \mathrm{C}$ amino acids into the LHCP of the thylakoids of the $\mathrm{Z}$ strain during the cell cycle. They found little incorporation up tp $6 \mathrm{hr}$ into the light period and a rapid rise to a peak at $10 \mathrm{hr}$ falling to low incorporation again by $18 \mathrm{hr}$ (4 hr into the dark period) with a slower decrease to the end of the dark period at $24 \mathrm{hr}$. Thus the staining in the Golgi, in the present work, starts earlier, rises more gradually, and falls more rapodly than the thylakoid labeling seen by Brandt and Von Kessel(1983). This is what one would expect if the LHCP passed through the Golgi on the way to the thylakoids early in the light period. 


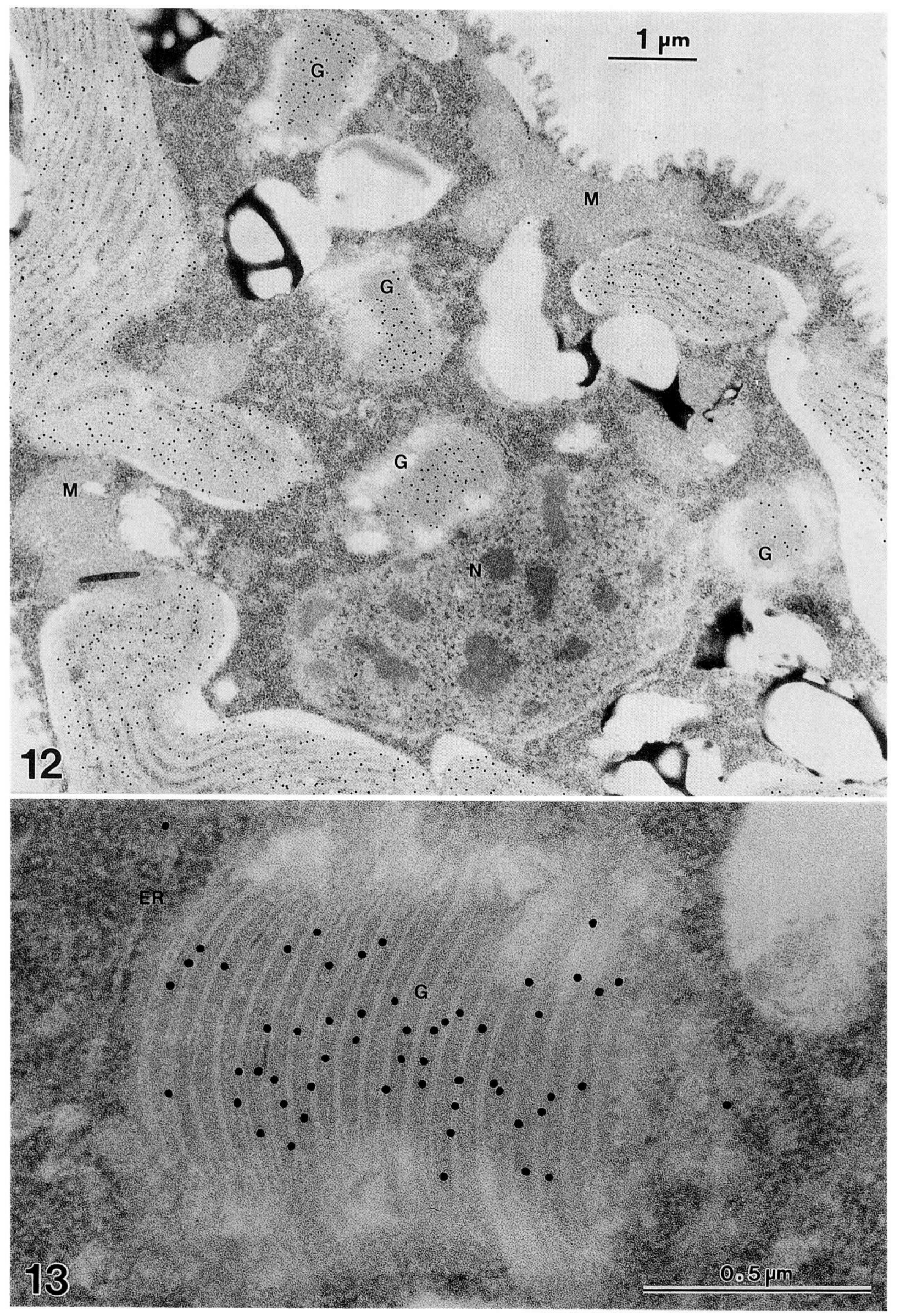




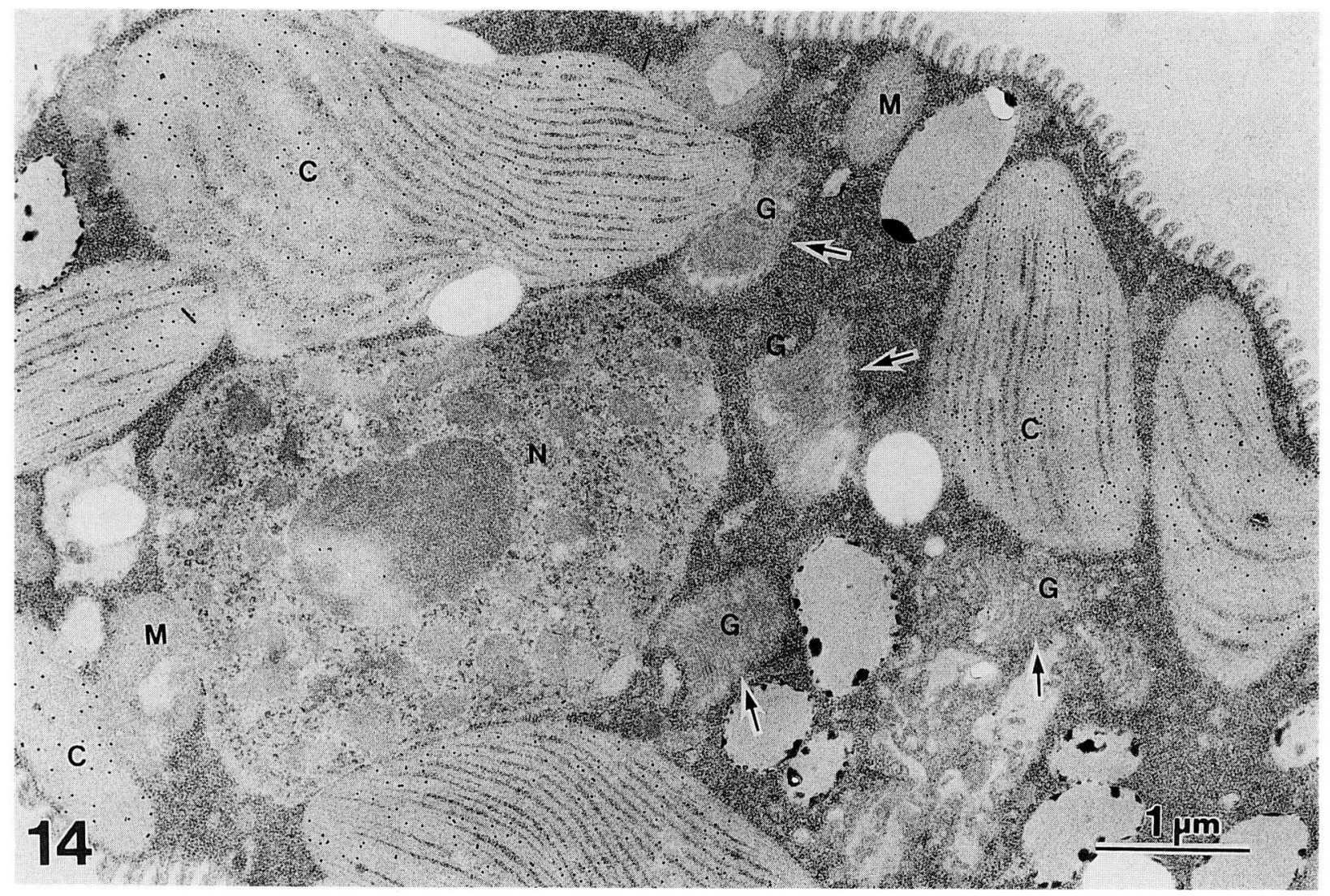

\section{Conclusion}

It would appear, from the data already presented, that the structure of Euglena pLHCP II, and the pathway by which it is transported to the chloroplast, may be unique. Large mRNAs containing multiple copies of the LHCP II structural genes are transcribed in darkness in wild-type cells and in mutants lacking plastids such as $\mathrm{W}_{10} \mathrm{BSmL}$. LHCP II mRNAs are translated into polyprotein precursors on ribosomes associated with the ER (either rough ER or, possibly, the $\mathrm{COS}$ ), and pLHCP is probably cotranslationally transported into the ER and passes from there into the Golgi where further modifications take place. From the Golgi, the present evidence suggests that the LHCP II polyprotein is transported to the plastids in Golgi vesicles which may fuse with the plastid envelope. An N-terminal transit peptide and internal prokaryotic signal peptides will permit an intact pLHCP II polyprotein to be translated through the chloroplast envelope for final polyprotein processing within the chloroplast. Alternatively, C-terminal prokaryotic signal sequences may allow LHCP IIs, which are cleaved from the polyprotein precursor before transport to the Golgi (possibly in the COS or ER), to be translated into the chloroplast for final processing to a mature protein.

The control of Euglena LHCP II synthesis by light (and other modulators) is exerted predominantly rather than at transcription as found in higher plants and other algae. In other organisms, for proteins which are cotranslationally transported into the ER, translation of the nascent protein is arrested by the interaction of the $\mathrm{N}$-terminal signal sequence with a signal 
thylakoids remain heavily stained with immunogold.

Figs.6 and 7. Dark-grown resting cell of Euglena gracilis var bacillaris exposed to light for 96 hr treated with anti-LHCP II apoprotein followed by protein A-gold. Note that no deposition of gold is observed over the Golgi apparatus (at the arrow) although the plastid thylakoids remain heavily stained with immunogold.

Fig. 8. Frequency of localization of LHCP II in the Golgi apparatus during the cell cycle of Euglena gracilis. Vertical bars represent the range variation in three observations.

Figs. 9 and 10. Two examples of serial sections of a cell at the beginning of the light period $(0 \mathrm{hr}$ cell) treated with anti-LHCP II followed by protein A-gold. Note that gold particles (immunoreaction with LHCP II antibody) are concentrated over thylakoids, but not Golgi apparatus. An arrow shows Golgi.

Fig. 11. A section through COS in a $1 \mathrm{hr}$ cell. Gold particles are highly concentrated over the COS.

Fig. 12. A low magnification of a section in a $10 \mathrm{hr}$ cell. Gold particles are concentrated over Golgi (4) and thylakoids.

Fig.13. A high magnification of a section in a $10 \mathrm{hr}$ cell. Note that gold particles are localized over both the Golgi cisternae membrane and dense material which lies between the cisternae as shown Fig.12.

Fig. 14. Low magnification of a cell of a $23 \mathrm{~h}$ cell. Note that gold particles were localized over the thylakoids in doughter chloroplasts, but not Golgi (4). Four arrows indicate Golgi.

\section{Referenses}

Ben-Shaul, Y., Schiff, J.A., and Epstein, H.T.(1964). Studies of chloroplast development in Euglena. Plant Physiol., 39, 231-240.

Brandt, P. and Von Kessel, B. (1983). Cooperation of cytoplasmic and plastidial translation in formation of the photosynthetic apparatus and its stage-specific efficiency. Plant Physiol., 72, 616-619.

Cunningham, Jr.,F.X., and Schiff, J.A.(1986). Chlorophyll-protein complexes from Euglena gracilis and mutants deficient in chlorophyll $b$. II. Polypeptide composition. Plant Physiol., 80, 231-238.

Greenblatt, C.L. and Schiff, J.A. (1959) A pheophytin-like pigment in dark adapted Euglena gracilis. J. Protozool., 6: 23-28

Houlne, G., and Schantz, R.(1987). Molecular analysis of the transcripts encoding the light-harvesting chlorophyll $a / b$ protein in Euglena gracilis: unusual size of the mRNA. Curr. Genet, 12, 611-616.

Muchhal, U., and Schwartzbach, S.D.(1990). Characterization of a Euglena chlorophyll $a / b$ 
binding protein (LHCP II) gene encoding a polypeptide precursor. Plant Physiol., 93, S-544.

Osafune, T., Klein, S., and Schiff, J.A.(1980). Events surrounding the early development of Euglena chloroplasts. 18. Structure of the developing proplastid in the first hours of illumination from serial sections of wild- type cells. J. Ultrastructure Res., 73, 77-90.

Osafune, T., and Schiff, J.A.(1983). $\mathrm{W}_{10} \mathrm{BSmL}$, a mutant of Euglena gracilis var. bacillaris lacking plastids. Exp Cell Res.148, 530-535.

Osafune, T., Schiff, J.A., and Hase, E.(1989a). Immunolocalization of LHCP II apoprotein in the Golgi of Euglena. In: Baltscheffsky, M. ed. Current research in photosynthesis Vol.III. Netherlands:Kluwer Academic Publishers. 735-738.

Osafune, T., Sumida, S., Ehara, T., and Hase, E.(1989b). Three-dimensional distribution of ribulose-1,5-bisphosphatecarboxylase/oxygenase in chloroplasts of actively photosynthesizing cell of Euglena gracilis. J. Electron Microsc., 38, 399-402.

Osafune, T., Ehara, T., Ito, A., and Hase, E.(1990a). Incorporation of cytoplasmic structures by developing proplastids in dark-grown Euglena gracilis cells transferred to an inorganic medium in darkness. J. Electron Microsc., 39, 168-171.

Osafune, T., Ehara, T., Tahara, M., and Hase, E.(1990b). Efects of blue and red light on chloroplast development in dark-grown wax-rich cells of Euglena gracilis transferred to inorganic medium. J. Electron Microsc., 39, 254-259.

Osafune, T., Ehara, T., Sumida, S., Hase, E., and Schiff, J.A. (1990c). Light- independent processes in the formation of thylakoids and pyrenoids in pro- plastids of dark-grown cells of Euglena gracilis. J. Electron Microsc., 39, 245-253.

Osafune, T., Sumida, S., Ehara, T., Ueno, N., Hase, E., and Schiff, J.A. (1990d). Lipid (wax) and paramylum as sources of carbon and energy for the early development of proplastids in dark-grown Euglena gracilis cells transferred to an inorganic medium.

J. Electron Microsc., 39, 372-381.

Osafune, T., Schiff, J.A., and Hase, E.(1990e). Immunogold localization of LHCP II apoprotein in the Golgi of Euglena. Cell Struct. Funct., 15, 99-105.

Osafune, T., Schiff, J.A., and Hase, E.(1991a). Immunolocalization of LHCP II apoprotein in the Golgi during light-induced chloroplast development in non-dividing Euglena cells.

J. Electron Microsc., 40, 41-47.

Osafune, T., Schiff, J.A., and Hase, E.(1991b). Stage-dependent localization of LHCP II apoprotein in the Golgi of synchronized cells of Euglena gracilis by immunogold electron microscopy. Exp. Cell Res., 193, 320-330.

Osafune, T., Sumida, S., Ehara, T., Schiff, J.A., and Hase, E.(1991c) in Regulation of Chloroplast Biogenesis (Argyroudi-Akoyunoglou, J.H., Ed.), pp.347-352, Plenum 
Publishing Company Ltd., New York.

Osafune, T.(1991d) Three-dimensional distribution of LHCP II apoprotein immunoreaction in synchronized cells of Euglena. Plant Morphology, 3,49-55.

Osafune, T., Schiff, J.A., and Hase, E.(1992). Accumulation of LHCP II apoprotein in wax-rich cells of Euglena in low light or in the presence of streptomycin. J. Structural Biol.,109, 97-108

Rikin, A., and Schwartzbach, S.D.(1988). Extremely large and slowly processed precursors to the Euglena light harvesting chlorophyll $a / b$ binding proteins of photosystem II. Proc. Natl. Acad. Sci. USA., 85, 5117-5121.

Rikin, A., and Schwartzbach, S. D.(1989). Regulation by light and ethanol of the synthesis the light harvesting chlorophyll $a / b$ binding protein of photosystem II in Euglena. Planta, 178, 76-83.

Schiff, J.A., Schwartzbach, S.D., Osafune, T., and Hase, E.(1991). Photocontrol and processing of LHCP II apoprotein in Euglena: Possible role of Golgi and other cytoplasmic sites. J. Photochem. Photobiol.,11, 219-236.

Shihira-Ishikawa, I., Osafune, T., Ehara, T., and Hase, E.(1977). An early light-independent phase of chloroplast development in dark-grown cells of Euglena gracilis Z. I. Dependence of the plastid development on previous culture conditions. Plant Cell Physiol., (Special issue), 445-454.

Spano, A.J., Ghaus, H., and Schiff, J.A.(1987). Chlorophyll-protein complexes and other thylakoid components at the low intensity threshold in Euglena chloroplast development. Plant Cell Physiol., 28, 1101-1108.

Spano, A.J.(1987). Euglena ferredoxin-NADP reductase, purification properties, and relationship to other thylakoid components during chloroplast development. $\mathrm{PhD}$ Dissertation, Brandeis University.

Stern, A.I., Schiff, J.A., and Epstein, H.T.(1964a). Studies of chloroplast development in Euglena. V. Pigment biosynthesis, photosynthetic oxygen evolution and carbon dioxide fixation during chloroplast development. Plant Physiol., 39, 220-226.

Stern, A. I., Epstein, H.T., and Schiff, J.A.(1964b). Studies of chloroplast development in Euglena. VI. Light intensity as a controlling factor in development. Plant Physiol., 39, 226-231.

Sulli, C. and Schwartzbach,S.(1995). The polyprotein precursor to the Euglena light harvesting chlorophyll alb-binding protein is transported to the Golgi apparatus prior to chloroplast import and polyproteinprocessing.J. Biol. Chem. 270, 13084-13090.

Sulli, C. and Schwartzbach,S.(1996). A soluble protein is imported into Euglena chloroplasts as a membrane-bound precursor. The Plant Cell, 8, 45-53.

Weiss, C., Houlne, G., Schantz, M.L., and Schantz, R.(1988). Photregulation of the synthesis of chloroplast membrane proteins in Euglena gracilis. J. Plant Physiol., 133, 521-538. 